\title{
Diffuse Esophageal Spasm
}

Taro Shibuki, Hiroharu Kawakubo, Kojiro Kawachi and Toshihiko Mizuta

Key words: diffuse esophageal spasm, dysphagia, corkscrew appearance

(Intern Med 56: 1447, 2017)

(DOI: 10.2169/internalmedicine.56.8240)

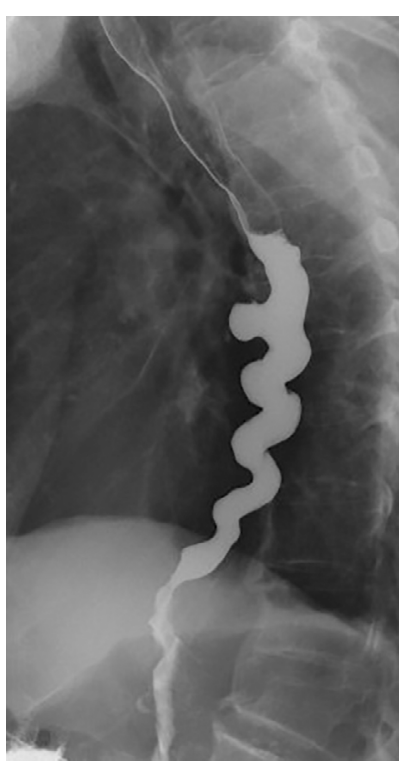

Picture 1.

An 82-year-old man was admitted to our hospital due to dysphagia. Barium esophagography showed the esophagus to have a corkscrew appearance (Picture 1). Esophagogastroduodenoscopy also showed similar findings (Picture 2). Given these typical imaging findings, he was diagnosed with diffuse esophageal spasm (DES), although esophageal manometry for a definite diagnosis could not be performed due to the patient's refusal. Proton pump inhibitors and calcium channel blockers were unable to improve his symptoms. However, he decided not to undergo further medical intervention such as endoscopic myotomy or balloon dilatation because switching his diet from solid foods to minced meal alleviated his dysphagia. DES is a rare esophageal motility

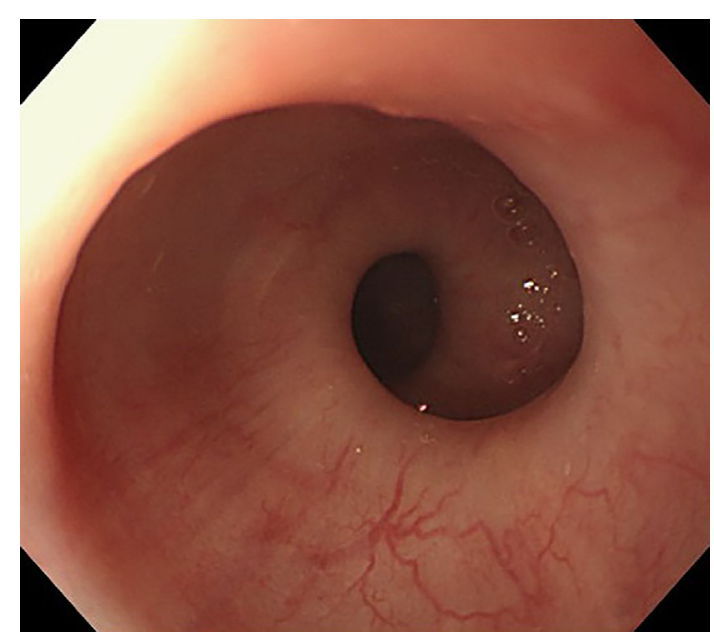

Picture 2.

disorder accompanied by dysphagia (1). Although it has been suggested that disordered neural inhibition caused by nitric oxide deficiency might be involved in the pathogenesis of DES, its mechanisms remain unclear. Striking "corkscrew" imaging can help diagnose DES.

The authors state that they have no Conflict of Interest (COI).

\section{Reference}

1. Patel DA, Vaezi MF. A spiraling case of persistent dysphagia. Diffuse esophageal spasm. Gastroenterology 149: 298-299, 2015.

The Internal Medicine is an Open Access article distributed under the Creative Commons Attribution-NonCommercial-NoDerivatives 4.0 International License. To view the details of this license, please visit (https://creativecommons.org/licenses/ by-nc-nd/4.0/).

Department of Internal Medicine, Imari Arita Kyoritsu Hospital, Japan

Received for publication September 8, 2016; Accepted for publication October 16, 2016

Correspondence to Dr. Toshihiko Mizuta, mizuta1221@gmail.com

(C) 2017 The Japanese Society of Internal Medicine Journal Website: http://www.naika.or.jp/imonline/index.html 